\title{
RESOLVING THE PROBLEM OF ALGORITHMIC DISSONANCE: AN \\ UNCONVENTIONAL SOLUTION FOR A SOCIOTECHNICAL PROBLEM
}

Shiv Issar | Department of Sociology, University of Wisconsin-Milwaukee | sissar@uwm.edu

June 29, 2021

Abstract

In this paper, I propose the concept of "algorithmic dissonance", which characterizes the inconsistencies that emerge through the fissures that lie between algorithmic systems that utilize system identities, and sociocultural systems of knowledge that interact with them. A product of human-algorithm interaction, algorithmic dissonance builds upon the concepts of algorithmic discrimination and algorithmic awareness, offering greater clarity towards the comprehension of these sociotechnical entanglements. By employing Du Bois" concept of "double consciousness" and black feminist theory, I argue that all algorithmic dissonance is racialized. Next, I advocate for the use of speculative methodologies and art for the creation of critically informative sociotechnical imaginaries that might serve a basis for the sociological critique and resolution of algorithmic dissonance. Algorithmic dissonance can be an effective check against structural inequities, and of interest to scholars and practitioners concerned with running "algorithm audits".

Keywords: Algorithmic Dissonance, Algorithmic Discrimination, Algorithmic Bias, Algorithm Audits, System Identity, Speculative methodologies. 


\section{Introduction}

This paper builds upon Aneesh's (2015) notion of system identities by utilizing their nature beyond their primary function of serving algorithmic systems and the process of algorithmic decisionmaking. As Aneesh (2015) describes, system identities are data-bound constructions built by algorithmic systems for the (singular) purpose of being used by algorithmic systems. They are meant to simulate a specific dimension (or a set of dimensions) of personhood, just as algorithmic systems and algorithmic decision-making are meant to simulate the agents of different social institutions, and the decisions that those agents would make. System identities are separate from both sociocultural identities and bureaucratic identities. As clouds of data, system identities are consistently in flux. Given that the demographics that they absorb (gender, income, region, education, to name a few) along with certain other "fluid" profiles (such as credit scores, buying habits, health profiles etc.), system identities are constantly shifting and changing within a diverse array of sociocultural contexts.

The paradox that system identities present is now well-known: Individuals are unable to "know" what their systems identities are like at any point of time. This is on account of how system identities operate in a computationally distributed way, where they change their self-definition within networks of systems whose operations are often obscured by proprietary code. It is impossible for an individual to actively negotiate with the formation of their system identity, or its classification within an algorithmic system. This equates the system identity with an algorithmic representation of a human being, and posits it as a more nuanced concept than that of a "data double", which bears some similarities, but is restricted to being a "form of pragmatics" (Haggerty and Ericson 2000).

The implications that the dynamics of system identities have for safeguarding and protecting themselves are most peculiar. For instance, surveillance is an expression of this form of protectionism, which works against the "theft" of an individual's system identity. It bears real-world 
consequences for patterns of social behavior or social activities that might not conform with what an algorithmic system might construe as "normative" (e.g.: suspicious credit-card activity). This creates a form of dissonance that the subject (or individual) experiences as a result of the tensions between their system identity and their sociocultural identity - tensions that are driven by the increasing dominance of algorithmic systems within a globalized, Habermasian "lifeworld" (Aneesh 2012). Aneesh (2015:94) goes on to describe how individuals often alter their behavior to influence their system identity (and its underlying profiles of parameters) at a given point of time. Here, Aneesh instantiates the interplay between our sociocultural identities and system identities through varied forms of "awkward" dissonance experienced by employees at a call center (e.g.: Nocturnal labor, "Neutral" markets) in India (pp. 101-125).

With Aneesh's framework in view, I make three arguments. Firstly, I argue for an expansion of the term "algorithmic dissonance", which has only been used in a very specific context. Cayley (2015) first utilized the term with respect to the practice of translation, where he uses it to describe a form of dissonance between how an algorithm might process a particular (natural) language in a way that is distinct from how a human would understand its morphological, grammatical or lexical specificities. I advocate for the term's use for all forms of algorithmic dissonance that might appear across on human-algorithm networks. Secondly, I show how all algorithmic dissonance is racialized. I turn towards black scholarship and the field of black studies to do so. Finally, I advocate for how varying forms of non-knowledge (or negative knowledge) can serve as a means of knowing more about how algorithmic dissonance can be addressed. To do so, I draw upon Ulrich Beck's conceptualization of the same (Beck 2009). Beck describes two forms of non-knowing: Unintended (or unconscious non-knowing), and Intentional (or conscious non-knowing). For cases of nonknowing that bear the features of both forms, a "precautionary" principle replaces the 
“compensatory" principle with respect to preventing large-scale catastrophes from occurring (p. 118). This precautionary principle must rely on the practice of imaginary scenario-building as opposed to any kind of corresponding "real world" experiences (p. 119). Only then can the multitude of potentialities that system identities offer be recognized, and the possibility of algorithmic dissonance occurring be better understood, and potentially minimized.

Keeping Beck's theory of non-knowing in mind, my recommendation for the emerging interdisciplinary field of critical algorithm studies is as follows: the legitimization of speculative methodologies/art as a source of information for the sociological critique of human-algorithm networks is of paramount importance, as is the use of more inclusive and speculative methodologies/art for the creation of critically informative sociotechnical imaginaries (Jasanoff 2015; Shabbar 2018; Reddy et al. 2019) that might help prevent instances of algorithmic dissonance from occurring. This recommendation rests on the assumption that it is possible for speculative methodologies to give life to forms of knowledge that could blur the boundaries between what is known and not-known on human-algorithm networks.

What is Algorithmic Dissonance?

A logic of algorithmic dissonance was first articulated by Cayley (2015), but restricted to the realm of translation work and linguistics. In an application of a procedurally-driven "longest common phrase algorithm" towards the translation of a section of Samuel Beckett's How It Is (Comment c'est), Cayley comes across certain discrepancies in the generated piece after it was translated from English into its original language, French (pp. 6-7). The original text serves as a basis for comparison with the algorithmically generated, quasi-original translation that includes sequences of words that were not 
originally written by Beckett. Cayley terms the rendering as being "quasi-algorithmic", owing to the ties that it bears to language employed by Beckett, and the role that algorithms play within composing its translation (p. 8).

It is easy to see how the algorithm employed by Cayley produces dissonance much in the way that Aneesh (2015:116) describes the production of (algorithmic) dissonance between system identities and the sociobiological realities of call center employees. Both cases are scaffolded by a paradigm: knowledge (as possessed by an algorithmic system) is system-specific, which is why it is impossible to witness the creation of "universal, transcendental knowledge" that lies independent of any system (or point) of observation (Luhmann 1984). Moreover, both cases relate to interactions that occur on a human-algorithm network - a term that I have intentionally hyphenated in order to allude to Latour's (1987) “Actor-Network Theory” - for algorithms do indeed possess a complex relationality with society. This relationality makes it possible for algorithms to exist and intervene within our lives as sociotechnical artefacts that produce scripts for us to act on with a great deal of specificity (Peeters 2020). Since Cayley (2015), the term "algorithmic dissonance" has formally reappeared in the work of Cleave (2020) who utilizes the term to describe how an algorithm's agency is restricted by tensions between two competing authorities. Cleave's undefined usage of the term contrasts against that of Cayley's, and presents the need for a clear and broad articulation of the term.

A simple definition of "dissonance" implies an apparent "lack of agreement", or "an instance of inconsistency/disagreement" (Merriam-Webster Dictionary 2020). Whilst using it to characterize the fissures or interstitial spaces between knowledge systems on human-algorithm networks, one could employ the term "algorithmic dissonance" and add more nuance in the process. 
A more precise and coherent definition of the term would be as follows: As a type of sociotechnical dissonance (Tian 2020), algorithmic dissonance refers to the inconsistencies that emerge through the fissures that lie between algorithmic systems that utilize system identities, and the sociocultural systems of knowledge that interact with them. Here, I echo the Luhmannian assertion: "the difference would become a driving force" (Luhmann 1984). With respect to the (human) actors upon whom this force is exerting itself, what must be pondered upon is whether the net effect of this exertion is positive or negative in the context of the actors' existential states and life courses.

It thus becomes crucial to understand the nature of the phenomenon of algorithmic dissonance. One might wish to recall Pickering's (1993) co-productionist metaphor of the "mangle" and think about how the processes of algorithmic decision-making can be delineated into algorithmic discrimination and algorithmic dissonance. Algorithmic dissonance is different from algorithmic discrimination, which occurs specifically when an individual or group is the recipient of unfair, inequitable treatment as a result of adversarial algorithmic decision-making (Goodman 2016)

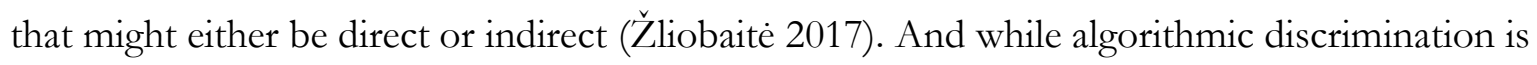
(debatably) a structuralist concept, I put forward the idea that algorithmic dissonance is a functionalist phenomenon that manifests itself at the level of the individual as a representation of (their) conflicting desires that create unpleasant tensions in the form that cognitive dissonance does (Abadeer 2015). In some ways, it can be dissipated if the individual experiencing it makes certain adjustments to their expectations, but this would require them to make compromises on what they had desired or hoped for (Lauer 2017) in the form of an algorithmically-produced decision, statement or output. Algorithmic dissonance also proves itself to be distinct from algorithmic bias, which exists in many forms (Danks and London 2017) and occurs when algorithmic systems either 
inherit the biases of their creators or the biases that rest within the data that they are being fed (Garcia 2016). The diagram below elaborates upon their relationality of the three concepts.

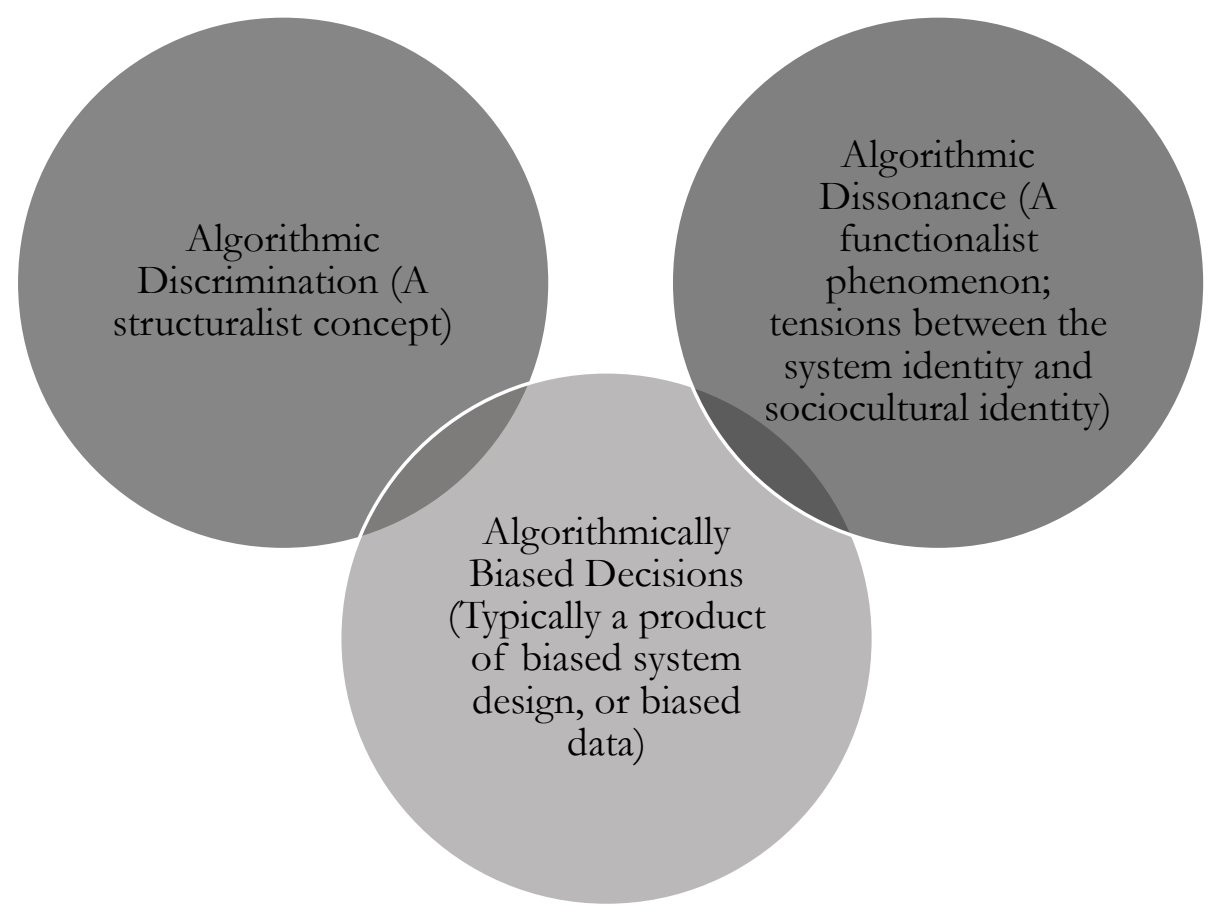

Figure 1: What algorithmic discrimination and algorithmic dissonance have in common as their base of production.

Users and scholars of algorithmic systems are becoming increasingly familiar with the idea of being "algorithmically aware" of bias in algorithmic systems (Eslami et al. 2017). Algorithm (or algorithmic) awareness is a disposition that characterizes the extent to which an individual is aware of their engagement with an algorithmic system (Eslami 2015). A prominent factor within these interactions and the construction of technocultural imaginaries (Hamilton et al. 2014), algorithm awareness has been called an important "internet skill" and a potential marker of the new digital divide (Gran et al. 2020). An understanding of algorithm awareness, as Bucher (2017) reports, is largely accessible through experience, or a phenomenological way of thinking about humanalgorithm interactions. Terms such as "algorithmic literacies" combine this sense of awareness with 
peoples' knowledge and "tactics around algorithms", and are distinct from the idea of being computer-literate or "digitally literate" (Swart 2021). If the term "algorithmic literacy" seems to overlap with the notion of an "algorithmic experience" (Alvarado and Waern 2018), it is because it does. The experiential focus, as Swart (2021) points out, is central to the formation of literacies that are "tacit, intuitive, situated, and lived" (Tuan 1977). The literature on algorithm awareness reveals that some "algorithmically aware individuals" are not only aware of an algorithm's influence on their identities, lives and social interactions, but that they are also aware of the extent to which they are influencing the algorithm (Koenig 2020), and how they are positioned as "rhetorically literate computer users" (Selber 2004) that simultaneously "consume and produce" within the realm of algorithmic culture. This underscores the centrality and significance of algorithm awareness with regard to the construction of algorithmic literacies and the comprehension of algorithmic experiences such as that of algorithmic dissonance.

What also strengthens the notion of algorithmic dissonance is the extant literature on algorithmic normativities. With the view of an algorithmic system as a sociotechnical assemblage, the literature on algorithmic normativities identifies a greater need for negotiability within algorithmic systems, whilst providing answers to the questions of where it might lie and how it could be harnessed. Algorithmic normativities make it irrelevant to "open" the black box (Lee and Larsen 2019) and approach algorithms as entities that are intertwined with both, the normative "human" expectations and the biased facets of algorithmic decisions alike. Lee and Larsen (2019) characterize the relationship between what is algorithmic and non-algorithmic within a system by viewing algorithms as artefacts that are imbued with three kinds of normativities: Behavioral, Technical and Sociotechnical. 
It is these normativities that enable algorithms to exercise a certain influence in its relationship with what is non-algorithmic. Negotiability, as Dudhwala and Larsen (2019) point out, appears at junction where interactions occur between algorithmic outputs and the people that engage with them. Take into consideration the plagiarism-checking software, TurnItIn, where the conditions under which an algorithmic decision has been made (with respect to the authenticity of an academic article) might need to be questioned (Introna 2016). The need for negotiability becomes apparent in such instances where a particular (algorithmic) output bears a diminished level of congruence with the expectations that people might have had (i.e., their normative expectations are partially or completely displaced by outputs that are governed by "algorithmic normativities"). This fits the characterization of algorithmic dissonance. A reduction of algorithmic dissonance (for an individual experiencing it) might emerge from the three pathways that have long been known to scholars of Festinger's cognitive dissonance theory (Smith 1969). A modification of those three pathways in the context of algorithmic dissonance can be written as follows: Algorithmic dissonance could potentially be reduced by altering of one (or more) of the components that are entangled within these (dissonant) sociotechnical relations, by adding either "human" or algorithmic components that would be consistent with prevailing cognitions, and/or by reducing the significance (or influence) of dissonant algorithmic components.

It is beyond the scope of this paper to actively talk about strategies that are focused on "reducing" algorithmic dissonance as it, as its primary goal is to address its resolution through preventative measures that could be incorporated within the design (and usage) of algorithmic systems instead. Moreover, the notion of algorithmic dissonance is only partially reliant upon the theory of cognitive dissonance, as the production of "psychological discomfort" (Harmon-Jones and Mills 2019) is primarily a product of dissonant algorithmic components. This is where it might be 
more utilitarian to turn towards the theorizations offered by Lee et al. (2019), who combat the focus on algorithms as "biased and opaque" black boxes to elaborate upon the nature of the associations within which they are embedded. They provide an explanation for how algorithms "fold" social/material entities, effects, and methods into their operations through three specific types of operations (proximation, universalization, normalization). The metaphor of the "black box" is thus replaced by an action of "folding" that follows Latour's lead; it describes an algorithmic "network" as consisting of both algorithmic and non-algorithmic (human/social) elements. I believe that these interpretations and theorizations (of algorithmic normativities and algorithmic operations) could assist with the formulation of a typology for algorithmic dissonance.

\section{"Non-Knowing" and the construction of System Identities}

To work towards the resolution of algorithmic dissonance is to work towards the resolution of a sociotechnical risk. To do so, I turn towards Ulrich Beck's "Risk Society” framework (Beck 2009), where our world (i.e., the "world risk society") is seen as a non-knowledge society. As a cognitive schema (p. 4), Beck's framework opens up an epistemological pathway for us to know risk in a reflexive manner (p. 19), and realize the potential of risk, which lays embedded within the very construction of system identities. Through an incorporation of probabilistic realities within the horizon of what is expected, Beck creates a union of what he calls "knowledge" and "nonknowledge", relating both of them to "modern risks" that reveal themselves on account of the market-driven use of large-scale technological and industrial apparatuses (pp. 30-46). Here, Beck makes a very precise distinction - "I do not speak of 'knowledge' or 'non knowing' in the cognitive sense common in philosophy, in the theory of science or in natural science, but in the sociological

sense, which construes 'knowledge' as expectation, as social attribution and construction”' (p. 115). 
Whilst establishing the nature of non-knowing as a "manufactured" existential condition (p. 116), Beck goes on to offer the dynamic nature of probabilistic scenarios as examples of what is construed as "knowledge" within certain spatiotemporal boundaries, or otherwise relegated to the dimension of "non-knowledge" or "non-knowing". At the junction where knowledge and non-knowledge meet, the reflexivity of risk manifests itself by providing a certain degree of protection against the dangers that it details, as it makes it possible for individuals (or entire communities) to determine a path for the future within the present itself. The power and potential of non-knowing in the Risk Society is such that it is omnipresent, and capable of altering many dimensions of human life (p. 115).

Beck delineates the concept of non-knowing into two types: Unintended non-knowing or the unintended-inability-to-know, and Intentional non-knowing (p. 118) or (to put it simply) "not wanting to know". With regard to assembly of system identities, the inclusion of elements of intentional non-knowing could predominantly stem from the user or subject of an algorithmic system, who might choose to dismiss any right to critically engage with the data that they are providing to the system. On the other hand, the inclusion of aspects of unintended non-knowing could be theorized more effectively through the use of concepts such as that of a "data void" (Golebiewski and Boyd 2020), and all the information that a system captures (or ignores). Data voids merit consideration as they highlight what is not known on account of data being limited, nonexistent, or deeply problematic. When viewed as vulnerabilities (or potential risks) within algorithmic systems, data voids reveal cultural prejudices and the potential to be exploited by a particular group (p. 6), making it logical to conceptualize them as "flaws", or as manifestations of unintended nonknowing within system identities. This would be congruent with what Golebiewski and Boyd (2020) state about the removal of data voids from an algorithmic system, for the act of replacing 
problematic content with high-quality content can only be carried out if the system itself structures system identities in a (highly utopian and potentially impossible) way that is not influenced by economic, political, or ideological gain (p. 7). System identities can thus be understood as databound constructs that rely on both forms of non-knowing against the backdrop of data capitalism.

A relevant example that ties the concept of non-knowing to the role of system identities in media culture can be seen in Havens' (2017) work, where he speaks of the "algorithmic audience" and the use of proprietary recommendation systems on the black users of streaming services such as Netflix and Hulu. The highly quantified "measurement" of the audience ends up playing a role in the curatorial practices that Netflix follows, along with the entire practice of content creation at their end as well. Here, one might be prompted to ask the following questions: Given Netflix's poor subscription rates amongst black communities, why is there no "good" quantitative measure of programming for black subscribers? What is it that is unconsciously not-known or willfully ignored with respect to Netflix's black audiences, and what sort of data voids is its information ecosystem sustaining or producing? And most vitally, how do these forms of non-knowing feed into the construction of system identities within Netflix's recommendation systems?

With Netflix's algorithms possibly exhibiting the assumption that black people would only be concerned with productions that have a majority of black actors, it would be hard to not see how this racist paradigm is the result of a decision based on poorly aggregated patterns of consumption that bear ties to the user profiles of its black users: a major source of data for their system identities, and a point of investigation for the presence of data voids. The multitude of potentialities that system identities offer can be recognized; another one would simply be the failure of Netflix's algorithms to recognize a black viewer (Havens 2020). This would be congruent with Kotliar's (2020) interpretation of algorithmic decision-making, where the behavioral characteristics of the 
users are favored over demographic/sociological ones (p. 1154). Little is known about the true nature of these proprietary algorithms, and demographic characteristics are supposedly not even utilized by them (p. 159). In order to minimize occurrences of Algorithmic Dissonance amongst Netflix's black users, Netflix's executives would have to explore an extensive number of imaginary scenarios that address the forms of non-knowing that its recommendation and measurement algorithms get entangled with. Such practices might attend to the pressing need of imagining and understanding systemic injustices that are embedded within these platforms (Floegel 2020).

The emergence of algorithmic dissonance within Netflix's user experience (UX) domain could pave the way for the operationalization of Beck's precautionary principle, which comes into effect when both forms of non-knowing materialize alongside the emergent need to prevent largescale catastrophes from occurring (Beck 2009). As Beck informs us, the use of the precautionary principle must rely on the practice of probabilistic and fictional scenario-building, as opposed to any kind of corresponding "real world" experiences that might rely on a mathematical "compensatory" principle instead (p. 119). This does not imply that the exercise of scenario-building would lack theoretical and methodological underpinnings. In the example involving Netflix, one could certainly segue into a rigorous conversation on "black data" through an imaginary of what it represents (and/or more crucially, what it ought to represent), the ways through which big data contributes to a system's understanding of black people, and the subsequent governance of their behaviors (McGlotten 2016). McGlotten uses interpretive and performative black queer practices in order to conceptualize the ties that black data bears to opacity, defacement, and encryption, suggesting that the methods could be imported within conversations on networks, software architects and information technology (p. 279). For the executives at Netflix, it would make sense to construct and explore multiple scenarios on the grounds that big data can certainly be reductive in the context of 
blackness. By foregrounding the limitations of race as a quantified entity, not only would they be able to better understand how black people and their system identities relate to each other, but how system identities and data voids come into existence as well.

\section{How is all Algorithmic Dissonance racialized?}

The articulation of "racialization" as a concept and a process has been centered around the "addition" of racial characteristics to a certain outlook or worldview (Barot and Bird 2001), though the same logic could extended to physical sites, economic models, or even human-algorithm networks. Depending on how the process works within a particular milieu, racialization could present itself as a problem which can only be resolved through the counter-process of deracialization, or the "removal" of racial characteristics from the vantage point of decision-making. Alternatively, racialization could act as a necessary response to the deracializing tendencies of democracies, which impose a certain kind of social-levelling upon a populace and hinder the achievement of equity (p. 606).

Barot and Bird (2001) explain that racialization could occur at the "centre" (pp. 607-608) of a political system where legislative and bureaucratic power is concentrated, and racial categorization (p. 609) occurs as an outcome of this structuration. On the other hand, it could also take place at the "periphery", where it could resemble a form of resistance to the hegemony and/or violence of the existing political status quo (p. 612). This marks the presence of racialized dissonance (HordgeFreeman and Veras 2020) in some cases. The presence of racialized and/or ethnoracial dissonance presents us with a rupture - a feeling of disidentification from certain racial schemas that are made available to a certain racial and/or ethnic minority (p. 4). This would be congruent with what Dixon- 
Román (2016) states about how both (human) bodies and algorithms are racialized, and the ways by which digital technologies are entrenched agencies that are racialized assemblages. Indeed, as Weheliye (2014) informs us, these racializing assemblages (or digital technologies) function as visual modalities through which dehumanization is both practiced and lived (p. 6). The technologies might distinguish along parameters other than race as well - such as nationality or religion - for there is no such thing as an "absolute" biopolitical substance (p. 52).

Hordge-Freeman and Veras (2020) evoke and utilize the Du Boisian concept of "double consciousness" in a conceptually similar fashion to how Parham (2019) does, albeit towards different ends. While Hordge-Freeman and Veras (2020) do so to speak of the embodiment of ethnoracial dissonance, Parham (2019) uses the concept to show us how contemporary technological innovation relies upon racialized algorithmic structures (p. 118) that could potentially reiterate racialized histories of oppression in a way that they might have absolutely nothing to do with an individual's own experiences and choices in the contemporary moment. Whilst referring to the Du Boisian “double consciousness", Parham (2019) provides an example of her own presence and activity on social media to describe how social media algorithms only offer a glimpse of her own algorithmic representation, or what this paper would refer to as the system identity. Black-boxed and sealed off within layers of proprietary code, Parham acknowledges that the constitution and formation of her algorithmic representation is obscured from her. The rendition of Parham's (2019) displaced, omnipresent digital "otherhood” implies that algorithmic dissonance certainly is a racialized phenomenon, since it forces the reiteration of a black identity that is simply not "hers" in an exclusive sense, but the product of complex, computational assemblages that reduce people to certain numerical values (i.e., system identities). The process - reductive as it is - would strip us of almost all of our individuality within an algorithmic ecosystem and create a limited degree of 
correspondence between what an algorithm might perceive as "representational of us" and what we believe to be an accurate and valid depiction of our personae.

The account presented by Parham (2019) proves itself to be sufficient for an inductive approach towards understanding all instances of algorithmic dissonance as racialized, as it possesses the potential for being thought of as a relatable phenomenon across different populations. The sites for racialization within an algorithmically governed world need not be fixed within the binary of the political centre and periphery, as they could, in effect, be located anywhere. Our participation in this system does not come without experiencing some sense of how invisible algorithms impress visible effects upon us in a manner that Parham aptly frames as "ghostly yet evidential, present yet temporally displaced” (p. 106).

Algorithmic dissonance could be experienced differently by different racial groups - a facet that would only strengthen the notion that it is a racialized phenomenon. Take, for example, how the act of travelling, particularly through airports, is an algorithmically mediated human experience these days. The absence or presence of whiteness would certainly have a bearing upon how algorithmic dissonance is experienced by a traveler, and the extent to which that form of algorithmic dissonance might affect them. For many black people and other people of color, as Hooks (1992) says, the act of travelling is one that would force an encounter with white supremacy (p. 174). This would correlate with what Simone Browne (2015) states in Dark matters: On the surveillance of blackness about the phenomenon of digital surveillance. Browne's book brings together black feminist theory, STS, and cultural studies into a dialogue with biometric technology through a situated critique of surveillance at airports - a sociopolitical norm for many of us. "Dark matters" elicit visions of opacity, restrictions upon that which is visible, boundaries upon the nature and essence of "blackness", and all that cannot be observed (p. 9). Black-boxed algorithms fuel anti-black 
technologies of surveillance, and bear a history with the practice of surveillance all the way back to the management of the transatlantic slave trade (pp. 10-11). Browne introduces us to our biometric pasts through a re-telling of the practice of branding enslaved people (pp. 90-100), delving into the problematic ways through which whiteness sustains the historicity of systematically branding information onto the system identities of black people through biometric information technologies (p. 109). Tethered and bound to racialized digital representations of non-whiteness, people of color experience the constant reiteration of histories of oppression and discrimination that are bound to the spatiotemporal histories of data (Dixon-Román 2016:3). These patterns reify the idea of a digital "otherhood", and characterize the experience of algorithmic dissonance as a racialized, sociotechnical phenomenon.

To add to this historicized setting, Kitchin (2014) states, "Data and their assemblage are thus co-determinous and mutually constituted, bound together in a set of contingent, relational and contextual discursive and material practices and relations” (p. 25). With this web of racialized relationality in the background, discriminatory and intrusive practices at airports (Browne 2015) become more than instances of algorithmic discrimination as they also present us with narratives of algorithmic dissonance being experienced. Safiya Noble’s (2018) use of black feminist and intersectional approaches towards the scrutiny of algorithmic biases and their production certainly seems to support this rationale by provoking a similar, vital line of inquiry within the realm of search engines and the algorithms that they employ.

With algorithms “seeing” people as multiplicities (Kotliar 2020) and working incessantly on creating new variations of system identities through never-ending streams of data, no social scientific definition of an "algorithmic identity" (p. 1154) can afford to ignore a racial context, even if a more technical definition of the concept accurately represents the preferences that algorithmic systems 
(and their constituent algorithms) exhibit for the behavioral characteristics of their users/subjects. Indeed, at least some, if not all algorithmic identities and any correlated experiences of algorithmic dissonance can certainly be seen as racialized. For if algorithms are inherently racist as Noble points them out to be, would that logic not lend itself to the lived and co-produced (Jasanoff 2004) experiences of algorithmic dissonance? All experiences of algorithmic dissonance are racialized, because of how structural racism seeps into the design of algorithmic systems and their decisionmaking.

Preventative solutions such as discrimination-aware data mining are only partially effective on account of the complexities presented by non-uniform population datasets (Žliobaitè 2017), and what is not-known about them. Williams et al. (2018) speak extensively about the nature of big data, social identifiers within big data, and all that algorithms lack in terms of information that leads to instances of algorithmic discrimination. They map instances of algorithmic discrimination over the entire life course, whilst paying specific attention to correlations and patterns of autocorrelations in social category data (pp. 82-83). The statistical practice of imputation and the use of proxy variables are brought up as the basis for understanding how algorithms form assumptions for an entire sample or population (p. 84), alongside a more detailed conversation on algorithmic bias as a product of statistical discrimination. This reifies what Beck had stated about non-knowing as the primary characteristic of the risk society, and place non-knowing at the heart of algorithmic dissonance. As an episteme and non-linear theory of knowledge, instances of non-knowing (as experienced by vulnerable individuals/communities) reveal numerous power differentials that are tied to the distribution of knowledge and non-knowledge (Beck 2009:125) and the consequent creation of latent/manifest threats for vulnerable populations. In this sense, insights from documented experiences of algorithmic dissonance might complement the practice of discrimination-aware data 
mining, and aid the prevention of biased decision-making. The following section details the necessity for speculative methodologies/art as the basis for following the precautionary principle and articulating what is not accounted for within a system identity, or a biased algorithmic decision.

\section{Resolving the problem of Algorithmic Dissonance}

Risk has been conceptualized in connection to blackness and the lived experience of being black in the postcolonial moment (Jackson 2014), paving the way for both microsociological and macrosociological frameworks of risk to be taken into consideration within the context of racialized, sociotechnical assemblages and the production of algorithmic dissonance. An alignment with epistemological pluralities (Colucci-Gray et al. 2013) is essential to the resolution of algorithmic dissonance, as it requires the decentering of a dominant episteme, the investigation of questions on identity (Sterling 2001). Within the context of various kinds of dissonance (social, sociotechnical, cognitive, emotional, cultural, economic etc.), an imagining of these epistemological pluralities as possible futures is not novel (Angheloiu et al. 2020; Carrillo Ocampo et al. 2021), but their application to the problem of algorithmic dissonance certainly is. A few pertinent approaches are reviewed within this section.

A focus on the production of epistemological pluralities would underscore the importance of Patricia Hill Collins' (2003) work on Afrocentric feminist epistemology, which effectively demonstrates how alternative epistemologies can be utilized to visualize viewpoints that are inclusive of multiple traditions or worldviews (p. 53). With respect to understanding algorithmic dissonance as a racialized experience for all people, Hill Collins' Afrocentric feminist epistemology might prove itself to be a template for the ways by which documented instances of algorithmic dissonance could 
be qualitatively examined at the level of the individual. The individual testimonial would certainly fulfill the role of providing "concrete experience as a criterion of meaning" (p. 54) whilst presenting the potential for contributing to aggregated repositories of information as coded interactions on a human-algorithm network. As narratives, the records of individuals' experiences with algorithmic dissonance might further inform our understanding of micro-level racial fluidity, and flaws within processes of stratification and racial identification that take place through policy (Saperstein and Penner 2012).

With respect to sociologically critiquing human-algorithm networks and focusing on the problem of algorithmic dissonance, a methodology that necessitates near-narrative exposition and analysis is that of Brock's (2018) Critical Technocultural Discourse Analysis (CTDA). Brock brings in the case study of "Black Twitter" and discusses the relevance of the Twitter user interface and the manner by which it serves as a point of access between an individual and an algorithmicallymediated system. Using CTDA, he examines how Twitter itself mediates discourse, with the hope that the use of the method would decenter normative perceptions on structural inequalities, prejudice, and biases in information communications technology (p. 16), but its multimodal use of data and emphasis on interface analysis stands to dilute the critique of experiences of algorithmic dissonance at the level of the individual.

Certain forms of narrativization have already made their way into critical algorithm studies, albeit from the perspective of studying datafication, and "ethnographically" examining algorithms (Seaver 2017; Christin 2020) and pushing past the limitations imposed by the "black box". The process of datafication is an extractive one that feeds into the production of algorithmic bias. As a practice, a phenomenon, and a paradigm, datafication influences multiple decisions about business, governance and technological innovation and carries little to no consideration for either consent or 
compensation for the subjects that it exploits (Ruckenstein and Schüll 2017; Sadowski 2019). Biased algorithmic systems become the vantage point from where discriminatory algorithmic decisions infiltrate society, whilst reinforcing and/or automating existing social inequalities. There are a series of complex relationships between the notion of digital labor and such value extraction, where affective relations are a critical component of the processes that lay embedded within the latter (Arvidsson and Colleoni 2012). Indeed, the sociotechnical analysis of digital labor would remain a futile enterprise without a great deal of focus on its "materializing" and relational aspects within physical office spaces and the larger urban landscape as well (Mahmoudi and Levenda 2016). As Dourish and Gómez Cruz (2018) state with respect to understanding data from an ethnographic perspective: "Data must be narrated—put to work in particular contexts, sunk into narratives that give them shape and meaning, and mobilized as part of broader processes of interpretation and meaning-making." Crucially, the algorithmic "treatment" (Lycett 2013) of datafication within the social sciences poses the necessity for a deeper discussion on the matter of algorithmic bias, as datafication tends to overlook or misrepresent certain facets of the material world, while adding others that might not have even existed to begin with. With respect to the (algorithmic) bias that emerges from the procedure of datafication, a strong case can be made for the examination of different kinds of bias in data and datasets alike, for they are both of human design (Crawford 2016).

Outside of the pursuit of narrativizing data, the use of speculative methodologies might prove itself to be very productive. Data capitalism draws surplus value from the potentialities that data exhibits - from the possibilities of what data might become (Dixon-Román and Parisi 2020) and what datafication might lead to in different techno-social futures. An endeavor made towards imagining these techno-social futures demands an acceptance of how race bears generative powers (Najar 2005) beyond the present moment; it corrals and sorts entire populations into groups that are 
then addressed through socially constructed taxonomies that bear ties to specific sociohistorical contexts (Desmond and Emirbayer 2009). Parham's (2019:102) use of “speculative frameworking” is but one example of a speculative method that could be utilized with respect to scrutinizing livable (albeit racialized) futures within the human-algorithm networks of the world risk society.

Upon broadening the scope of engagements with speculative methodologies, one would also come across the work of Ruha Benjamin (2016), who utilizes Afrofuturism and situates a fictional story within biopolitical discourses of the present. Using a short story by Du Bois ("The Comet") as their source of inspiration, Benjamin stresses upon the importance of (speculative) storytelling in both scholarly and civic praxis. Given the possible variations within how the same form of algorithmic dissonance might be experienced differently by different racial and/or ethnic groups, Benjamin's method of speculative storytelling presents the possibility for a greater deal of inclusivity in the face of algorithmically-produced inequities. Their story, "Ferguson is the Future", articulates a demand for biological citizenship (Petryna 2004) that rests upon existing health inequities, and problems of access to resources and infrastructure that are almost always circumscribed within state surveillance, and the (largely automated) classification of populations.

New forms of art can certainly be used in a critically-informative way here as well. My usage of "art” within a sociotechnical milieu parallels that of Luhmann's (Luhmann and Roberts 1985) within the social: "Whether literature or theatre, plastic arts or music - all are relevant as long as social communication treats the object (by whatever criteria) as a work of art" (p. 4). In speaking to the assertion that art shares the fate of society (p. 6), Ratner and Ruppert's (2019) work questions the status of algorithms as technical objects by stressing the need to attend to aesthetic practices that would illustrate the possibilities presented by algorithmic normativities. What they mean by this is that data itself is aestheticized (through practices such as data visualization) at sites where it is 
projected/dispersed, such as a data portal. Functionally, these sites of projection lend a voice to the normativities embedded within algorithmic governance that would have otherwise been silenced by narratives of opacity. The horizon of the speculative methodologies also includes art that enables new perceptions and articulations of the algorithmic. An example would be "glitch" art - a "critical and creative mode of protest against (sexual) surveillance" that establishes itself by exposing and exploiting the fallibility of algorithmic recognition technologies (Shabbar 2018). Vries and Schinkel (2019) contend that the "academic" analyses of algorithmic technologies can be informed (and also inspired) by "artistic, algorithmic imaginaries". They consider artworks that focus on countering the surveillance effects of facial recognition through masking or camouflage, reflecting the essence of the algorithmic imaginary.

In the interest of comprehending the tensions produced by these data-bound, algorithmic asymmetries, speculative methodologies/art must be given greater consideration in order to examine how these algorithmic misrepresentations and biases lead to the production of algorithmic dissonance at the microsociological level. The testimonial of the individual - imagined, visualized, or recorded - could prove to be a strong guiding force with respect to aiding the incorporation of lived realities and historical circumstances within digital entities. There is growing acceptance of ideas such as Algotaylorism (or Algorithmic Taylorism), which relates to the extreme division of labor and pre-configured reduction of the worker to click-based gestures in the digital economy (Digicult 2020), and the large-scale generation of what David Graeber once aptly called "bullshit jobs" (Besteman and Gusterson 2019). This model coexists along the notion of a "machinic illusion" (EFlux 2020) where work that is assumed to have been automated by technology is actually being performed by people. Having evolved as a group exhibition in France, algotaylorism has its roots in the idea that contemporary wage-work or work stemming from the "gig economy" bears a great 
degree of resemblance to artistic practices, seeing how there has been a boom in the number of selfemployed contractual workers over the past decade (Launay 2020). As of December 2020, the curator, Aude Launay, is currently working on a second exhibition on the idea of algotaylorism, titled "Rage Against the Machine", where she shifts her focus onto analyzing how machines have been trained to recognize and define both work and workers (Gantner 2020). Aside from being informative for the concept of algorithmic dissonance, it is easy to see how both exhibitions also tie in with Lilly Irani's studies on microwork that is carried out on Amazon Mechanical Turk (AMT) and its methods of worker control (Irani 2013), as well as her work on how duplicity builds up within systems that do not clarify whether machinic labor or poorly-compensated human labor is being put to use (Irani 2015). This relates to Adorno's idea of “truth content" or Wahrheitsgehalt (Zuidervaart 2015) in art, where an engagement with artistic truth is seen as an engagement with dynamics that are "dialectical, disclosive, and nonpropositional". Arbitrations bound within the fabric of the social and the milieu of the sociotechnical as essential to resolution of algorithmic dissonance for "discursive choices also form an important element in most institutional efforts to shore up new structures of scientific authority" (Jasanoff 2004). The decision to bring art and other speculative methodologies into mainstream discourse of critical algorithm studies may remain a contested one for a while, but it certainly is a decision that is worth pondering upon as one attempts to expand its frontiers.

There are many other speculative methodologies that could be listed here, but exploring them summarily would not do them justice, and doing so in detail would go beyond the scope of this paper. It would, however, be sufficient to say that on the basis of Beck's precautionary principle, the use of speculative methodologies would indeed, produce a more thorough sociological understanding of human-algorithm networks, and the way in which the problem of algorithmic 
dissonance could be resolved. The entanglements that these methods present us with might serve as a pathway for an imagining of human-machine synthesis beyond the current status quo of human-

machine dualisms. They could (at least in theory) assist the development of complex cyber-physical systems (Trevino 2019) that might actually be capable of accounting for a sense of more "human" self-perception and individuality in the act of framing system identities. Then, and perhaps only then, would the phenomenon of algorithmic dissonance cease to be an element of the present, and become a memory of our future's past.

\section{Recommendations for Researchers and Practitioners}

The resolution of algorithmic dissonance requires greater transparency in algorithmic decisionmaking, insofar that it might enable an articulation (and the usage) of the rights that people have with respect to the creation and usage of their system identities. Benjamin's (2019) work adds to what is known about the construction of race in a world that is being increasingly infiltrated by technology. With critical race theory as a key framework, Benjamin clarifies how emerging technological paradigms are reinforcing white supremacy and racial discrimination in society. Their concept of the "anti-black box" could be tied in directly with Aneesh's concept of the system identity, and my proposed expansion for the definition of algorithmic dissonance within this paper. Together, the three concepts represent a union that synthesizes the conversation on humanalgorithm networks, racialized sociotechnical experiences and algorithmic governance as a whole. The myriad forms of stratification that emerge within an algorithmically-mediated society are a testament to how algorithmic dissonance is racialized, and why different forms of non-knowing must be targeted for what they could potentially narrativize with regard to social inequalities. 
Studies on algorithmic dissonance might produce narratives that would aid the development of algorithmic literacies within the general public. It is vital to acknowledge that algorithmic literacies are not necessarily contingent upon possessing deep insights into the inner workings of algorithmic systems, and the ways by which different algorithms are structured, situated, and used by corporations, governments, or other actors. A very basic level of algorithm awareness is sufficient for an understanding of how ranking systems and recommendation systems function (DeVito et al., 2017; DeVito et al., 2018), and only sufficiently advanced levels of algorithm literacy would consist of some comprehension of the theoretical aspects of how algorithmic systems are developed, and perhaps even how algorithms are "written" by their developers. Higher levels of algorithmic literacy and trust in algorithmic systems bear a positive correlation with each other (Benjamin et al. 2020), and both variables would possibly bear a strong negative correlation with the possibility of having experienced algorithmic dissonance.

Finally, seeing how algorithmic dissonance has been shown to affect different racial groups differently, it would be prudent to think about how it could also affect people from differing socioeconomic classes, genders, age groups and geographies. Keeping that in mind, future research on algorithmic dissonance would be best approached through the formation of a typology for algorithmic dissonance, and psychosocial investigations of the relationships between the experience of algorithmic dissonance and the actions that it directs at the level of the individual. 


\section{References}

Abadeer, Adel S. Z. 2015. “Cognitive Dissonance and Gender Discrimination.” Pp. 115-25 in Norms and Gender Discrimination in the Arab World, edited by A. S. Z. Abadeer. New York: Palgrave Macmillan US.

Alvarado, Oscar, and Annika Waern. 2018. “Towards Algorithmic Experience: Initial Efforts for Social Media Contexts." Pp. 1-12 in Proceedings of the 2018 CHI Conference on Human Factors in Computing Systems, CHI '18. New York, NY, USA: Association for Computing Machinery.

Aneesh, Aneesh. 2012. "Negotiating Globalization: Men and Women of India’s Call Centers." Journal of Social Issues 68(3):514-33.

Aneesh, Aneesh. 2015. Neutral Accent. Duke University Press.

Angheloiu, Corina, Leila Sheldrick, and Mike Tennant. 2020. "Future Tense: Exploring Dissonance in Young People's Images of the Future through Design Futures Methods.” Futures 117:102527. doi: 10.1016/j.futures.2020.102527.

Arvidsson, Adam, and Elanor Colleoni. 2012. "Value in Informational Capitalism and on the Internet.” The Information Society 28(3):135-50. doi: 10.1080/01972243.2012.669449.

Barot, Rohit, and John Bird. 2001. "Racialization: The Genealogy and Critique of a Concept.” Ethnic and Racial Studies 24:601-18. doi: 10.1080/01419870120049806.

Beck, Ulrich. 2009. World at Risk. Polity.

Benjamin, Jesse Josua, Claudia Müller-Birn, and Simon Razniewski. 2020. "Examining the Impact of Algorithm Awareness on Wikidata's Recommender System Recoin.” ArXiv Preprint. 
Benjamin, Ruha. 2016. "Racial Fictions, Biological Facts: Expanding the Sociological Imagination through Speculative Methods." Catalyst: Feminism, Theory, Technoscience 2(2):1-28. doi: $10.28968 /$ cftt.v2i2.28798.

Benjamin, Ruha. 2019. Race After Technology: Abolitionist Tools for the New Jim Code. Wiley.

Besteman, Catherine, and Hugh Gusterson, eds. 2019. Life by Algorithms: How Roboprocesses Are Remaking Our World, Besteman, Gusterson.

Brock, André. 2018. “Critical Technocultural Discourse Analysis.” New Media \& Society 20(3):101230. doi: $10.1177 / 1461444816677532$.

Browne, Simone. 2015. Dark Matters: On the Surveillance of Blackness.

Bucher, Taina. 2017. "The Algorithmic Imaginary: Exploring the Ordinary Affects of Facebook Algorithms." Information, Communication \& Society 20(1):30-44. doi: 10.1080/1369118X.2016.1154086.

Carrillo Ocampo, Julia C., Matilda Marshall, Lotte Wellton, and Inger M. Jonsson. 2021. "When Sustainable Cuisine Imaginaries Become Unsustainable: Storage and Preservation Practices in Swedish Restaurants." International Journal of Gastronomy and Food Science 24:100353. doi: 10.1016/j.ijgfs.2021.100353.

Cayley, John. 2015. “Beginning with 'The Image' in How It Is When Translating Certain Processes of Digital Language Art.” Electronic Book Review. Retrieved (https://electronicbookreview.com/essay/beginning-with-the-image-in-how-it-is-whentranslating-certain-processes-of-digital-language-art/). 
Christin, Angèle. 2020. "The Ethnographer and the Algorithm: Beyond the Black Box." Theory and Society 49(5):897-918. doi: 10.1007/s11186-020-09411-3.

Cleave, Peter. 2020. "Of Kings and Cobots.” Te Kaharoa 15(1). doi: https://doi.org/10.24135/tekaharoa.v15i1.322.

Colucci-Gray, Laura, Anna Perazzone, Martin Dodman, and Elena Camino. 2013. "Science Education for Sustainability, Epistemological Reflections and Educational Practices: From Natural Sciences to Trans-Disciplinarity." Cultural Studies of Science Education 8(1):127-83. doi: $10.1007 / \mathrm{s} 11422-012-9405-3$.

Crawford, Kate. 2016. "Can an Algorithm Be Agonistic? Ten Scenes from Life in Calculated Publics." Science, Technology, \& Human Values 41(1):77-92.

Danks, David, and Alex London. 2017. “Algorithmic Bias in Autonomous Systems.” Pp. 4691-97 in IJCAI.

Desmond, Matthew, and Mustafa Emirbayer. 2009. “What Is Racial Domination?” Du Bois Review: Social Science Research on Race 6(2):335-55. doi: 10.1017/S1742058X09990166.

DeVito, Michael A., Jeremy Birnholtz, Jeffery T. Hancock, Megan French, and Sunny Liu. 2018. "How People Form Folk Theories of Social Media Feeds and What It Means for How We Study Self-Presentation.” Pp. 1-12 in Proceedings of the 2018 CHI Conference on Human Factors in Computing Systems, CHI '18. New York, NY, USA: Association for Computing Machinery.

DeVito, Michael A., Darren Gergle, and Jeremy Birnholtz. 2017. “'Algorithms Ruin Everything’: \#RIPTwitter, Folk Theories, and Resistance to Algorithmic Change in Social Media.” Pp. 
3163-74 in Proceedings of the 2017 CHI Conference on Human Factors in Computing Systems, CHI '17. New York, NY, USA: Association for Computing Machinery.

Digicult. 2020. “What Is Work in the Globalized Digital Age? 'Algotaylorism’ Replies.” Digicult | Digital Art, Design and Culture. Retrieved December 17, 2020 (http://digicult.it/it/digimag/what-is-work-in-the-globalized-digital-age-algotaylorismreplies/).

Dixon-Román, Ezekiel. 2016. “Algo-Ritmo: More-Than-Human Performative Acts and the Racializing Assemblages of Algorithmic Architectures." Cultural Studies $\leftrightarrow$ Critical Methodologies 16(5):482-90. doi: 10.1177/1532708616655769.

Dixon-Román, Ezekiel, and Luciana Parisi. 2020. "Data Capitalism and the Counter Futures of Ethics in Artificial Intelligence." Communication and the Public 5(3-4):116-21. doi: $10.1177 / 2057047320972029$.

Dourish, Paul, and Edgar Gómez Cruz. 2018. "Datafication and Data Fiction: Narrating Data and Narrating with Data.” Big Data \& Society 5(2):2053951718784083. doi: $10.1177 / 2053951718784083$.

Dudhwala, Farzana, and Lotta Björklund Larsen. 2019. "Recalibration in Counting and Accounting Practices: Dealing with Algorithmic Output in Public and Private.” Big Data \& Society 6(2):2053951719858751. doi: 10.1177/2053951719858751.

E-Flux. 2020. “Group Exhibition : Algotaylorism.” Retrieved December 22, 2020 (https://www.eflux.com/announcements/307957/group-exhibition-algotaylorism/). 
Eslami, Motahhare. 2015. "Exposure to the Invisible: Algorithm Awareness from the Individual to the Collective.” P. 2 in. Urbana, IL.

Eslami, Motahhare, Kristen Vaccaro, Karrie Karahalios, and Kevin Hamilton. 2017. “"Be Careful; Things Can Be Worse than They Appear': Understanding Biased Algorithms and Users’ Behavior Around Them in Rating Platforms." Proceedings of the International AAAI Conference on Web and Social Media 11(1).

Floegel, Diana. 2020. "Labor, Classification and Productions of Culture on Netflix." Journal of Documentation 77(1):209-28. doi: 10.1108/JD-06-2020-0108.

Gantner, Espace multimédia. 2020. “Algotaylorism, Rage Against the Machine.” Espace Multimédia Gantner. Retrieved December 22, 2020 (https://www.espacemultimediagantner.cg90.net/?post_type=exposition\&p=3501).

Garcia, Megan. 2016. "Racist in the Machine: The Disturbing Implications of Algorithmic Bias." World Policy Journal 33(4):111-17.

Golebiewski, Michael, and Danah Boyd. 2020. "Data Voids: Where Missing Data Can Easily Be Exploited." Data \& Society.

Goodman, Bryce W. 2016. “A Step Towards Accountable Algorithms?: Algorithmic Discrimination and the European Union General Data Protection.” P. 9 in. Barcelona: NIPS Foundation.

Gran, Anne-Britt, Peter Booth, and Taina Bucher. 2020. “To Be or Not to Be Algorithm Aware: A Question of a New Digital Divide?" Information, Communication \& Society 0(0):1-18. doi: 10.1080/1369118X.2020.1736124. 
Haggerty, Kevin D., and Richard V. Ericson. 2000. "The Surveillant Assemblage." The British Journal of Sociology 51(4):605-22. doi: 10.1080/00071310020015280.

Hamilton, Kevin, Karrie Karahalios, Christian Sandvig, and Motahhare Eslami. 2014. "A Path to Understanding the Effects of Algorithm Awareness." Conference on Human Factors in Computing Systems - Proceedings. doi: 10.1145/2559206.2578883.

Harmon-Jones, Eddie, and Judson Mills. 2019. "An Introduction to Cognitive Dissonance Theory and an Overview of Current Perspectives on the Theory." Pp. 3-24 in Cognitive dissonance: Reexamining a pivotal theory in psychology, 2nd ed. Washington, DC, US: American Psychological Association.

Havens, Timothy J. 2017. “The Algorithmic Audience and African American Media Cultures Tim Havens / University of Iowa - Flow.” Retrieved November 28, 2020 (http://www.flowjournal.org/2017/10/the-algorithmic-audience/).

Havens, Timothy J. 2020. "Algorithmic Audience Modeling and the Fate of African American Audiences." Journal of Cinema and Media Studies 60(1):158-62. doi: https://doi.org/10.1353/cj.2020.0071.

Hill Collins, Patricia, Yvonna S. Lincoln, and Norman K. Denzin. 2003. “Towards an Afrocentric Feminist Epistemology." Pp. 47-72 in Turning Points in Qualitative Research: Tying Knots in a Handkerchief. Rowman Altamira.

Hooks, Bell. 1992. "Representing Whiteness in the Black Imagination.” Pp. 165-78 in Black looks: Race and representation. 
Hordge-Freeman, Elizabeth, and Edlin Veras. 2020. "Out of the Shadows, into the Dark:

Ethnoracial Dissonance and Identity Formation among Afro-Latinxs." Sociology of Race and Ethnicity 6(2):146-60. doi: 10.1177/2332649219829784.

Introna, Lucas D. 2016. “Algorithms, Governance, and Governmentality: On Governing Academic Writing." Science, Technology, \& Human V alues 41(1):17-49. doi: 10.1177/0162243915587360.

Irani, Lilly. 2013. “The Cultural Work of Microwork.” New Media \& Society 17(5):720-39. doi: $10.1177 / 1461444813511926$.

Irani, Lilly. 2015. "Difference and Dependence among Digital Workers: The Case of Amazon Mechanical Turk.” South Atlantic Quarterly 114(1):225-34. doi: 10.1215/00382876-2831665.

Jackson, Shona N. 2014. "Risk, Blackness, and Postcolonial Studies: An Introduction.” Callaloo 37(1):63-68. doi: 10.1353/cal.2014.0002.

Jasanoff, Sheila. 2004. "States of Knowledge | The Co-Production of Science and the Social Order." Taylor \& Francis. Retrieved October 19, 2019 (https://www.taylorfrancis.com/books/e/9780203413845).

Jasanoff, Sheila. 2015. Dreamscapes of Modernity. Chicago, London: The University of Chicago Press.

Kitchin, Rob. 2014. The Data Revolution: Big Data, Open Data, Data Infrastructures and Their Consequences. SAGE.

Koenig, Abby. 2020. “The Algorithms Know Me and I Know Them: Using Student Journals to Uncover Algorithmic Literacy Awareness.” Computers and Composition 58:102611. doi: 10.1016/j.compcom.2020.102611. 
Kotliar, Dan M. 2020. “The Return of the Social: Algorithmic Identity in an Age of Symbolic Demise.” New Media \& Society 22(7):1152-67. doi: 10.1177/1461444820912535.

Latour, Bruno. 1987. Science in Action: How to Follow Scientists and Engineers Through Society. Harvard University Press.

Lauer, Angela. 2017. “The Psychology of Cognitive Dissonance and Racism.” Reallifepsych. Retrieved December 12, 2020 (https://www.reallifepsych.com/single-post/2017/08/16/thepsychology-of-cognitive-dissonance-and-racism).

Launay, Aude. 2020. “Algotaylorism.” La Kunsthalle, Centre d'art Contemporain Mulhouse. Retrieved December 22, 2020 (http://kunsthallemulhouse.com/evenement/algotaylorism/).

Lee, Francis, Jess Bier, Jeffrey Christensen, Lukas Engelmann, Claes-Fredrik Helgesson, and Robin Williams. 2019. “Algorithms as Folding: Reframing the Analytical Focus.” Big Data \& Society 6(2):2053951719863819. doi: 10.1177/2053951719863819.

Lee, Francis, and Lotta Björklund Larsen. 2019. "How Should We Theorize Algorithms? Five Ideal Types in Analyzing Algorithmic Normativities.” Big Data \& Society 6(2):2053951719867349. doi: $10.1177 / 2053951719867349$.

Luhmann, Niklas. 1984. "The Self Description of Society: Crisis Fashion and Sociological Theory." International Journal of Comparative Sociology 25(1-2):59-72. doi: 10.1163/156854284X00052.

Luhmann, Niklas, and David Roberts. 1985. "The Work of Art and the Seff-Reproduction of Art." Thesis Eleven 12(1):4-27. doi: 10.1177/072551368501200102. 
Lycett, Mark. 2013. “'Datafication': Making Sense of (Big) Data in a Complex World.” European Journal of Information Systems 22(4):381-86. doi: 10.1057/ejis.2013.10.

Mahmoudi, Dillon, and Anthony Levenda. 2016. "Beyond the Screen: Uneven Geographies, Digital Labour, and the City of Cognitive-Cultural Capitalism.” TripleC: Communication, Capitalism \& Critique. Journal for a Global Sustainable Information Society.

McGlotten, Shaka. 2016. "Black Data.” doi: 10.1215/9780822373711-014.

Merriam-Webster Dictionary. 2020. "Definition of DISSONANCE.” Retrieved November 26, 2020 (https://www.merriam-webster.com/dictionary/dissonance).

Najar, Lubna. 2005. "The Chicago Poetry Group: African American Art and High Modernism at Midcentury." Women's Studies Quarterly 33(3/4):314-23.

Noble, Safiya Umoja. 2018. Algorithms of Oppression: How Search Engines Reinforce Racism. NYU Press.

Parham, Marisa. 2019. “Sample | Signal | Strobe:: Haunting, Social Media, and Black Digitality.” Pp. 101-22 in Debates in the Digital Humanities 2019, edited by M. K. Gold and L. F. Klein. University of Minnesota Press.

Peeters, Rik. 2020. “The Agency of Algorithms: Understanding Human-Algorithm Interaction in Administrative Decision-Making." Information Polity 25(4):507-22. doi: 10.3233/IP-200253.

Petryna, Adriana. 2004. "Biological Citizenship: The Science and Politics of Chernobyl-Exposed Populations." Osiris 19:250-65.

Pickering, Andrew. 1993. "The Mangle of Practice: Agency and Emergence in the Sociology of Science." American Journal of Sociology 99(3):559-89. doi: 10.1086/230316. 
Ratner, Helene, and Evelyn Ruppert. 2019. "Producing and Projecting Data: Aesthetic Practices of Government Data Portals.” Big Data \& Society 6(2):2053951719853316. doi: $10.1177 / 2053951719853316$.

Reddy, Elizabeth, Baki Cakici, and Andrea Ballestero. 2019. "Beyond Mystery: Putting Algorithmic Accountability in Context.” Big Data \& Society 6(1):2053951719826856. doi: $10.1177 / 2053951719826856$.

Ruckenstein, Minna, and Natasha Dow Schüll. 2017. “The Datafication of Health." Annual Review of Anthropology 46(1):261-78. doi: 10.1146/annurev-anthro-102116-041244.

Sadowski, Jathan. 2019. "When Data Is Capital: Datafication, Accumulation, and Extraction.” Big Data \& Society 6(1):2053951718820549. doi: 10.1177/2053951718820549.

Saperstein, Aliya, and Andrew M. Penner. 2012. "Racial Fluidity and Inequality in the United States." American Journal of Sociology 118(3):676-727. doi: 10.1086/667722.

Seaver, Nick. 2017. "Algorithms as Culture: Some Tactics for the Ethnography of Algorithmic Systems.” Big Data \& Society 4(2):2053951717738104. doi: 10.1177/2053951717738104.

Selber, Stuart A. 2004. Multiliteracies for a Digital Age. SIU Press.

Shabbar, Andie. 2018. "Queer-Alt-Delete: Glitch Art as Protest Against the Surveillance Cis-Tem.” Women's Studies Quarterly 46(3 \& 4):195-212.

Smith, Mahlon Brewster. 1969. Social Psychology and Human Values: Selected Essays. Transaction Publishers. 
Sterling, Stephen. 2001. Sustainable Education: Re-Visioning Learning and Change. Schumacher Briefings.

Schumacher UK, CREATE Environment Centre, Seaton Road, Bristol, BS1 6XN, England (6 pounds).

Swart, Joëlle. 2021. "Experiencing Algorithms: How Young People Understand, Feel About, and Engage With Algorithmic News Selection on Social Media.” Social Media + Society 7(2):20563051211008828. doi: 10.1177/20563051211008828.

Tian, Min. 2020. "Innovation through Digitalization: How Sociotechnical Tensions Drive Innovation.” Doctoral Dissertation in Business Administration, Stockholm School of Economics, Stockholm, Sweden.

Trevino, Marty. 2019. “Cyber Physical Systems: The Coming Singularity.” PRISM 8(3):2-13.

Tuan, Yi-Fu. 1977. Space and Place: The Perspective of Experience. University of Minnesota Press.

de Vries, Patricia, and Willem Schinkel. 2019. “Algorithmic Anxiety: Masks and Camouflage in Artistic Imaginaries of Facial Recognition Algorithms." Big Data \& Society 6(1):2053951719851532. doi: 10.1177/2053951719851532.

Weheliye, Alexander G. 2014. Habeas Viscus: Racializing Assemblages, Biopolitics, and Black Feminist Theories of the Human. Duke University Press.

Williams, Betsy Anne, Catherine F. Brooks, and Yotam Shmargad. 2018. "How Algorithms Discriminate Based on Data They Lack: Challenges, Solutions, and Policy Implications.” Journal of Information Policy 8:78-115. doi: 10.5325/jinfopoli.8.2018.0078. 
Žliobaitè, Indrè. 2017. “Measuring Discrimination in Algorithmic Decision Making.” Data Mining and Knowledge Discovery 31(4):1060-89. doi: 10.1007/s10618-017-0506-1.

Zuidervaart, Lambert. 2015. “Theodor W. Adorno” edited by E. N. Zalta. The Stanford Encyclopedia of Philosophy. 